\title{
ESTRUTURALISMO DE CELSO FURTADO E O NEOESTRUTURALISMO DE FERNANDO FAJNZYLBER: PREOCUPAÇÕES DESENVOLVIMENTISTAS CONVERGENTES
}

Structuralism of Celso Furtado and the Neostructuralism of Fernando Fajnzylber: convergent developmental concerns

Silvio Antonio Ferraz CARIO Universidade Federal de Santa Catarina (UFSC) fecario@yahoo.com.br

Lucas CORREAA Universidade Federal de Santa Catarina (UFSC) correa.lucas@outlook.com.br

Maria Luísa Lacerda ALBERTÃO Universidade do Vale do Rio dos Sinos (UNISINOS) luisalacerdalb@gmail.com

\begin{abstract}
RESUMO
O estudo sobre desenvolvimento econômico foi central nas obras de Celso Furtado e Fernando Fajnzylber. Ambos tiveram passagem profissional pela CEPAL, cujo método histórico-estruturalista influenciou fortemente seus escritos ao longo do tempo. A preocupação em explicar as razões do atraso econômico da América Latina, levou a convergência de ideias em vários temas. Nesse sentido, o objetivo desse artigo é apresentar pontos comuns nos tratamentos sobre o progresso técnico, capital multinacional, desenvolvimento comparado, Estado e projeto nacional de desenvolvimento. Para tanto, recorreu-se às principais obras dos autores que tratam essas categorias de análise. No geral, os resultados apontam problemas econômicos estruturais e decisões políticas de desenvolvimento limitadas impossibilitaram a construção de um desenvolvimento capitalista mais autônomo. E, em linha com os autores, somente um projeto nacional de desenvolvimento de médio e longo prazos e voltado ao interesse da sociedade, pode sinalizar novos caminhos desenvolvimentistas.

Palavras-chave: Desenvolvimento econômico. Pensamento de Celso Furtado e Fernando Fajnzylber. Progresso técnico. Projeto de desenvolvimento.
\end{abstract}

\begin{abstract}
The study of economic development was central to the works of Celso Furtado and Fernando Fajnzylber. Both had professional experience at CEPAL, whose historical-structuralist method strongly influenced their writings over time. The concern to explain the reasons for the economic backwardness in Latin America, led to the convergence of ideas on several themes. In this sense, the objective of this article is to present common points in the treatments of technical progress, multinational capital, comparative development, State and national development projects. For this, the main work of the authors that deal with these categories of analysis were used. Overall, the results point to structural economics problems and limited political development decisions made it impossible to build more autonomous capitalista development. And, in line with the authors, only a national medium and long-term development project, aimed at society's interest can signal new developmental paths.
\end{abstract}

Key-words: Economic development. Thought of Celso Furtado and Fernando Fajnzylber. Technical progress. Development project.

Classificação JEL: 01.010.

Recebido em: 06-11-2020. Aceito em: 02-12-2020. 


\section{INTRODUÇÃO}

Na América Latina, a Comissão Econômica para a América Latina e o Caribe (CEPAL), órgão vinculado à Organização das Nações Unidas (ONU), criado em 1948, constitui um espaço institucional voltado em produzir conhecimentos que dão suporte para aplicação de políticas públicas os governos da região. A instituição conta com equipe técnica formada por profissionais representantes dos países membros, cujas atividades de pesquisa e ensino demonstram preocupações voltadas em promover o desenvolvimento regional. Várias teses marcam os trabalhos da CEPAL: defesa da industrialização como caminho para superação do subdesenvolvimento; Estado exercendo funções de planejar, intervir e regular, no propósito de acelerar as condições de desenvolvimento; desenvolvimento do progresso técnico como instrumento para reduzir a heterogeneidade estrutural e superar a dependência tecnológica forânea; e defesa da equidade, igualdade de oportunidade, inclusão social e sustentabilidade ambiental.

A CEPAL foi espaço de trabalho profissional, em momentos distintos, de Celso Furtado e Fernando Fajnzylber. Ao redor dos escritos e de debates realizados com outros intelectuais, realizaram pesquisas - relatórios, artigos e livros - apontando os caminhos, os problemas e as propostas de superação do atraso econômico da região. Mesmo após passar por certo período nessa instituição, como Furtado; e, passar e retornar após seguir outros caminhos profissionais, como Fajnzylber, os escritos dos autores mantiveram bases metodológicas histórico-estruturalistas de interpretação do desenvolvimento econômico latino-americano. Ao longo de toda trajetória profissional, Furtado apresentou preocupações com temas mais amplos do desenvolvimento, abordando questões não somente econômicas, mas políticas, sociais e culturais. Enquanto, Fajnzylber, teve trabalhos concentrados em aspectos econômicos do desenvolvimento em grande parte da trajetória profissional, e em seus últimos trabalhos incorporou as questões social e ambiental como determinante chave do desenvolvimento.

No conjunto, ambos autores consideraram o desenvolvimento como processo de transformação econômica, política e social. Tratara-se como uma ordem transformadora da estrutura de uma sociedade, que permite evolução na melhoria no do padrão de vida da população. Não é algo dado, mas alcançado a partir de construção história, com respeito das características econômica, sociais e políticas localizadas. Para ser alcançado exige, determinação, vontade, ação e planejamento da sociedade. Contudo, o desenvolvimento 
não se processa de forma isolada, ocorre considerando o movimento do capitalismo em nível mundial, que se reproduz de forma heterogênea e sob influência e até impositiva de quem determina o padrão de acumulação em vigor.

Sob esse contexto, Furtado e Fajnzylber realizaram estudos visando compreender a realidade econômica, identificar os obstáculos estruturais e propor políticas e instrumentos para promoção do desenvolvimento latino-americano. Considera-se, nesses estudos, a existência de muitos pontos convergentes em temas desenvolvimentistas tratados por Furtado e Fajnzylber. Trazer à luz do debate acadêmico pontos convergentes de temas acerca do desenvolvimento, constitui o objetivo deste texto. Figura-se como um resgate de temas, que embora passado vários anos continuam vivos e presentes, dado que sempre há inquietação acerca dos problemas estruturais que impedem alcançar patamar maior de desenvolvimento, bem como os caminhos a serem seguidos para superar o atraso que nos persegue historicamente.

Em atendimento a esse propósito, o presente artigo encontra-se dividido em cinco seções. Nessa primeira seção, expressa-se o objetivo principal. Na segunda seção, apresenta-se a visão de Furtado acerca das categorias analíticas selecionadas: progresso técnico, capital estrangeiro, experiência de desenvolvimento, Estado e projeto nacional de desenvolvimento. Na terceira seção, discute-se o tratamento de Fajnzylber para as mesmas categorias analíticas. Na quarta seção compara-se, de forma sintética, o quadro analítico das categorias estudadas. E, por fim, na quinta seção, faz-se a conclusão.

\section{DESENVOLVIMENTO ESTRUTURALISTA EM CELSO FURTADO: PONTOS SELECIONADOS}

A influência das ideias de desenvolvimento da CEPAL sobre o pensamento de Celso Furtado foi significativa. Em pauta, o entendimento de que a passagem de uma economia agroexportadora para uma economia de base industrial levaria a América Latina em geral, e o Brasil, em particular, para o caminho do desenvolvimento. Nesse contexto, encontravase o deslocamento do centro dinâmico das atividades econômicas focada para o mercado externo, direcionasse para o mercado interno. Na leitura de Furtado, o período que seguiu a Grande Depressão de 1930 fora marcado de tensões econômicos no Brasil - crescimento econômico reduzido, inflação em alta, desvalorização cambial, déficit público elevado, declínio na capacidade de importação e renegociação da dívida externa -, que criaram 
condições domésticas para os esforços direcionarem à expansão da estrutura industrial (FURTADO, 1970; 2007).

Nessa linha interpretativa, a transformação estrutural ocorria sob processo de substituição de importações em setores ligados ao mercado interno, baseado em bens de consumo final e se estendendo a bens intermediários. Tais segmentos industriais eram incentivados por lucros, poupança interna e transferência de capitais do setor exportador e atendiam a demanda de população de centros urbanos em crescimento, na mesma linha interpretativa de Tavares (1977) e Mello (1998). Com a internalização das atividades econômicas baseada na indústria, geravam-se efeitos econômicos e sociais transformadores. Nessa linha, Furtado (1954, p. 42 e 44, apud Almeida 2009, p. 54) afirmou: “(...) a economia industrial (...) não encontra fatores que limitem tão definitivamente sua expansão”. Assim como, o “(...) o crescimento industrial exige que uma parte do aumento da produtividade alcançado pelo conjunto da economia, seja transferida aos consumidores finais para que se mantenha o ritmo de crescimento.

Furtado acreditava na expansão do sistema industrial a partir das inovações tecnológicas, consideradas a base de transformação das sociedades modernas. Sendo mais específico, considerava as inovações tecnológicas essenciais ao desenvolvimento do capitalismo industrial" (FURTADO, 1964). Em sua concepção, as inovações ao serem introduzidas de forma sistemática, gerariam capacidade de expansão produtiva, promoveriam relações interindustriais e intersetoriais e contribuiriam para a integração de mercados de várias regiões do país. No seu rastro, gerariam emprego, renda e bem estar social a população, possibilitando, assim, que as atividades econômicas gerassem efeitos sociais positivos.

Contudo, diante do desempenho da economia brasileira no início dos anos 60 , expressa por crise econômica marcada por estagflação e crise política que resultou no Golpe de Estado em 1964, Furtado reviu, a exemplo de outros economistas, como Tavares e Serra (2000), a visão de que com a industrialização o país estaria no caminho do desenvolvimento. Entendeu que não bastava industrializar, que o desenvolvimento seria alcançado. O modelo de desenvolvimento instaurado era diferente dos alcançados nos países desenvolvidos, que apresentavam processos histórico, econômico e social distintos. Logo, trazer, simplesmente, capital e técnicas de outros países avançados não geravam transformações na economia brasileira, em geral, e não criava uma economia industrial nacional autônoma, em particular (FURTADO, 1961). 
Nesse sentido, buscou explicações teórica-analítica para entendimento do subdesenvolvimento, não como uma etapa anterior do desenvolvimento, mas produto do próprio desenvolvimento capitalista. Esse vínculo, ainda que seguidor do sistema hegemônico mundial, possuía dinâmica própria, historicidade e curso distinto (ALMEIDA, 2009). Em suas palavras: "O fenômeno do subdesenvolvimento apresenta-se sob variadas formas e em diferentes estádios" (FURTADO, 1961, p. 161). Nesse sentido, apresentavase como expressão de como as elites dos países centrais, através de domínio sobre capitais, monopolizavam e apropriavam excedentes, em nível mundial, impondo estilo de desenvolvimento semelhante ao existente em seus espaços nacionais. Reproduziam-se na periferia o padrão de produção e consumo dos países centrais, do qual apenas uma parte da população doméstica tinha acesso e benefício.

Portanto, as possibilidades de transformações econômicas e sociais nas economias latino americana e brasileira eram reduzidas. Esta concepção era realimentada pela visão que tinha do comportamento do empresário nacional. De quem comanda o processo de acumulação, pouco poderia se esperar, dada as suas qualidades: incapacidade de comando, falta de mentalidade empreendedora, busca pelo lucro fácil, caminho pela imitação e permanente estado de desânimo. Suas afirmações foram reveladoras: “(...) a nova classe capitalista industrial sem experiência e carente de maior profundidade de visão, encontrou, via de regra, em concessões a grupos externos a linha de menor resistência para a solução de seus problemas ocasionais (FURTADO, 1964, p. 132); e, "(...) parece ocioso inquirir se existe nos países latino-americanos uma classe industrial com maturidade e sentido de identidade nacional, capacidade de encabeçar o processo de desenvolvimento dos respectivos países (FURTADO, 1968, p. 132).

Nesse sentido, ações propositivas de construção do desenvolvimento capitalista nacional não se constituíram, ainda que houvessem adeptos, em determinado momento, da ideologia nacional-desenvolvimentista. Certos segmentos da intelectualidade e políticopartidária brasileira achavam que a união do Estado e empresariado nacional poderia provocar transformações econômica e sociais de interesse da Nação (CARDOSO, 2020) Porém, essa concepção finda-se com o Golpe de Estado 1964, que sob comando dos militares, passou a imperar um estilo de desenvolvimento de capitalista associado, com a junção de interesses do Estado, capital multinacional e capital nacional ditando o padrão de desenvolvimento modernizante e conservador do país (FURTADO, 1966).

Em complemento, as dificuldades de adentrar outro caminho para o desenvolvimento nacional achavam-se limitadas pelo movimento e comando do desenvolvimento capitalista 
mundial. O desenvolvimento capitalista mundial do pós-Guerra, encontrava-se sob domínio hegemônico norte-americano, que determinava sua expansão na região latino-americana. Caminho diferente desse atrelamento e influência dependeria da tolerância norteamericana, e não se mostrava possível o país aceitar mais defecções em sua área de influência (FURTADO, 1966). Nessa perspectiva, abriram-se as portas para a internacionalização da economia. Empresas multinacionais, norte-americanas e de outros países capitalistas centrais, adentraram em segmentos industriais até então não presente na estrutura produtiva do país, com atividades voltadas em atender o mercado interno (TEIXEIRA, 1983).

A vinda de empresas multinacionais, que poderia ser considerada de comportamento racional para o desenvolvimento capitalista, tinha outras implicações. Ao ter controle majoritário nos setores de bens de capital e bens de consumo duráveis, segmentos com fortes vínculos para frente e para trás na estrutura produtiva passaram a ter elevado controle sobre o processo de produção de riqueza. Essas detinham o domínio tecnológico na fabricação de máquinas e equipamentos e de produtos de maior valor agregado e com forte interação com fornecedores domésticos. Com parte não desprezível da produção industrial subordinando-se às estratégias empresariais forâneas, os interesses econômicos estrangeiros se colocavam acima dos interesses nacionais.

Nesses termos, a internacionalização das atividades econômicas traria consequência debilitadoras para o centro de decisão nacional. No âmbito microeconômico, grandes empresas oligopolistas internacionais, em linha com as suas matrizes, detinham a direção, o ritmo e o valor da produção e investimento no país. Com esse domínio, subordinavam e desarticulavam as decisões econômicas das empresas nacionais, colocando-as com funções secundárias ou complementares, no exercício de fornecedoras na divisão de trabalho reinante. Tal domínio, estendia-se no campo macroeconômico, cujas decisões empresariais externas impactavam as variáveis básicas da economia nacional. Ao voltarem as atividades para o mercado interno e não assumirem compromisso com mercado externo, criavam-se possibilidades de crise no balanço de pagamento, dadas as importações insumos e equipamentos, amortizações de empréstimos e remessas de lucro que realizavam (FURTADO, 1968).

Para Furtado (1974), a divisão internacional do trabalho criou economias periféricas dependentes por irradiar valores culturais dos países centrais, que passaram a moldar suas estruturas econômicas e sociais. O controle dos fluxos produtivos, tecnológicos e financeiros pelos países centrais possibilitou os países centrais subordinarem, através da 
divisão internacional do trabalho, as economias periféricas, via a imposição do padrão de produção e consumo desejado. Com isso, a dependência decorria da própria estrutura do sistema econômico mundial e se realimentava em expansão territorial. Ao assim proceder, reproduziam desequilíbrios econômicos e disparidades sociais na área periférica, de difícil correção tais como maiores disparidades de níveis de vida entre grupos de população e acumulação de desemprego aberto disfarçado (FURTADO, 1966).

Em continuidade a visão pessimista do que a industrialização, sob comando das multinacionais nos principais setores, levasse a superação do subdesenvolvimento, Furtado (1972, p. 8) assim expressou: “(...) a tese que prevaleceu imediatamente após a guerra, de que a industrialização constitui razão suficiente para a absorção do subdesenvolvimento, está certamente desacreditada". Era bem verdade de que o país constituiu um parque industrial moderno e diversificado, sob controle de grandes empresas monopolista detentoras de tecnologia, mas que serviu para modernizar hábitos de consumo de uma pequena parte da população, que seguia a evolução cultural dos países desenvolvidos (ALMEIDA, 2009).

Para Furtado, o progresso técnico constituía a fonte da reprodução da acumulação capitalista e razão das condições do desenvolvimento dos países desenvolvidos. Nesse sentido, afirmou: "(...) a acumulação rápida que nestas nações tinha lugar constituía o motor das transformações capitalistas. Existe, portanto, uma íntima interdependência entre a evolução da tecnologia nos países industrializados e as condições históricas do seu desenvolvimento econômico" FURTADO, 1961, p. 84). Por conseguinte, beneficiava os países que o detinham o domínio do progresso técnico, e subordinava os que não o possuíam. Nesse entendimento, observou: "Nos países desenvolvidos, o fluxo de novos produtos e o complexo de inovações tecnológicas que os acompanham são essenciais ao funcionamento da economia capitalista, no âmbito mundial tais fatores operam no sentido de preservar as relações de dependência e dominação que caracterizam a economia internacional" FURTADO, 1972, p. 13).

Nessa perspectiva, a capacidade de introduzir e difundir progresso técnico no contexto das relações econômicas no sistema mundial tende a gerar condições de desenvolvimento e subdesenvolvimento. A dualização entre tais estágios de desenvolvimento teria no progresso técnico sua fonte determinante. No curso do desenvolvimento capitalista criavam-se hiatos tecnológico entre nações, que resultavam em padrão de apropriação de excedente ao longo do tempo pelos detentores do progresso técnico. Por sua vez, o hiato tecnológico seria aumentado pelo acesso ao conhecimento e 
ampliação da fronteira tecnológica pelos países do centro, em detrimento das dificuldades de acessar, compreender, absorver, dominar, usar e difundir conhecimento, pela periferia (FURTADO, 1983b). Daí a dificuldade de desfazer a dependência tecnológica e dos conhecimentos necessários à geração, difusão e uso pelas economias periféricas (GUIMARÃES et al, 2007).

Assim, a tecnologia adotada na economia da periferia era, para Furtado, fator estranho para a promoção do desenvolvimento. A correlação entre aumento da produtividade decorrente da relação capital-trabalho e do emprego de novas técnicas de produção não resultava no crescimento da massa salarial, de forma abrangente. Enquanto, nas economias desenvolvidas, o progresso técnico promovia aumento da produtividade que se fazia acompanhar pela disponibilidade de produtos e queda dos seus preços, em linha com a expansão da massa salarial e elevação do padrão de vida da população. Essa ocorrência nas economias subdesenvolvidas se manifestava nos segmentos considerados modernos - indústria de bens de capital e de bens de consumo duráveis, por ex. - que apresentavam aumentos de produtividade via progresso técnico, cujos produtos beneficiavam somente os grupos sociais de elevada renda. Por consequência, a grande maioria da população ficava à margem desse estilo de desenvolvimento.

Momento importante de renascimento da esperança de mudança desse quadro ocorreu quando Furtado (1978; 1992a) concluiu estudos sobre o desenvolvimento alcançado por países, que conseguiram superar a dependência externa imposta pela ordem mundial. Os estudos sobre a Rússia, China, Japão, Coréia e Taiwan demonstraram como foi possível recuperar a soberania nacional, através de projetos de desenvolvimento com foco em transformações econômicas e sociais. Esses países interromperam a transmissão de valores culturais gerados pelos países centrais, que realimentavam as condições de subdesenvolvimento e a manutenção da dependência externa A matriz dessa superação foi dar condições para que a criatividade humana interna se colocasse a serviço do desenvolvimento das forças produtivas e da diversificação dos padrões de vida da coletividade (ALMEIDA, 2009). Tais países estabeleceram estratégia soberana e audaciosa de desenvolvimento e travaram luta intensa contra a dependência externa.

Nesse contexto, passou a defender com ênfase que somente através do fomento à criatividade humana posta em termos de novas ideias, novos esforços, novos propósitos, enfim sob novas condições poderiam emergir soluções com propósito de resolver os problemas estruturais e superar o atraso econômico e social, em que se encontrava a América Latina em geral, e o Brasil em particular. No seu entendimento, tornava 
requerimento importante, a construção de vontade coletiva da sociedade voltada em recuperar a autonomia e soberania nacional, bem como seguir a orientação de convivência pacifica e de condições governáveis entre os povos (FURTADO,1992a; 1992b). Caberia o Estado criar condições para que a criatividade humana aflorasse nas dimensões econômicas, sociais e culturais a favor do desenvolvimento. Assim como, ter atuação ativa na coordenação, promoção e seleção de investimentos, na formação de recursos humanos, no fomento à pesquisa e desenvolvimento entre outras ações (FURTADO, 1978; ALMEIDA, 2009).

O Estado ao longo de sua vasta obra tem importância crucial por criar condições para o desenvolvimento na periferia, dada as carências estruturais existentes. Os papéis de produtor, interventor, controlador, planejador, financiador e gestor estão presentes, dado não acreditava que o desenvolvimento ocorresse de forma espontânea, sem orientação e sem direção. O Estado sempre foi visto como espaço que cria programa para a economia de mercado se desenvolver. Mesmo realizando críticas à passividade dos Estados da América Latina aos interesses do capital multinacional, permitindo que esse adentrasse em setores estratégicos, não ficasse sujeito a política seletiva de controle nacional, pautasse os investimentos estatais as estratégias estrangeiras e fosse partícipe de um modelo de desenvolvimento concentrador de renda, acreditava no exercício do Estado na promoção do desenvolvimento latino-americano. Suas palavras refletem essa observação: “(...) na América Latina para transformar-se em efetivo instrumento de desenvolvimento, requer prévia recuperação do Estado nacional como centro básico de decisão" (FURTADO, 1968, p. 117).

Diante da dependência e subdesenvolvimento existentes, Furtado (1983b) amplia a visão de que o Estado deveria ter controle sobre as empresas multinacionais, mesmo sob contexto de que são consideradas importantes para o desenvolvimento nacional. Essas deveriam subordinar-se aos interesses da Nação. Nesse sentido, sugere que o Estado deveria apropriar de parte dos lucros das empresas multinacionais e até estatiza-las se necessário. Assim como, subordinar tais empresas às diretrizes da política econômica nacional, seja macroeconômica, comercial, industrial e tecnológica. Da mesma forma, deveria controlar o ingresso do progresso técnico sob domínio das multinacionais, e obrigalas a adequar suas técnicas em função de objetivos sociais. A afirmação a seguir retrata a razão dessas proposições: “(...) não se trata de restringir arbitrariamente a ação das empresas transnacionais, e sim de orientá-las no sentido de dar prioridade ao mercado nacional e criação de emprego" (FURTADO, 1983a, p. 37). 
Furtado (1999a e 1999b) realçava a importância de se considerar a dimensão tecnológica, portanto um fator econômico; porém, não de forma isolada, mas junto com os fatores não econômicos, dentre os quais o processo social. Sinalizava que pensar em desenvolvimento do progresso técnico em economias subdesenvolvidas, marcadas por significativa heterogeneidade, deveria ser feito à luz do interesse social. Nesse sentifo, afirmou: “(...) não é possível captar a natureza (nem o impacto) destas modificações caso o progresso técnico seja circunscrito apenas ao plano macro, ou microeconômico, isolandoo de seu caráter social'. Segue outra afirmação: “(...) por detrás do progresso técnico se alinham complexas modificações sociais, cuja lógica deve-se tentar compreender como passo prévio a qualquer estudo do desenvolvimento (FURTADO, 1983b, p. 75, apud GUIMARÃES et al, 2007, p. 225). Por conseguinte, a compreensão dos fenômenos relacionados ao avanço tecnológicos, deve ser realizada a partir de perspectiva ampla e sistêmica, com conteúdo social.

Nos termos propostos, para Furtado era fundamental incorporar a dimensão social na compreensão de desenvolvimento econômico. Desenvolvimento não significava apenas transformação econômica, em que se modernizam parques fabris, realizam investimentos, melhoram condições infraestruturais, elevam níveis de produtividade, entre outros ganhos econômicos, mas, também, provocador de transformação social. Nesse contexto, afirmou: "Só haverá verdadeiro desenvolvimento - que não se deve confundir com crescimento econômico, no mais das vezes resultado de mera modernização das elites - ali onde existir um projeto social subjacente" (FURTADO, 1992b, p. 35). Seguindo tal raciocínio, o paradigma produtivo em vigor gerava crescimento econômico, mas seus frutos não eram distribuídos para a maioria da população. Requeria-se reconstruir a estrutura econômica rompendo com o paradigma anterior, e tal reconstrução somente seria possível através de um Projeto Nacional.

Como observa Lins (2013), o Projeto de Nação de Furtado contemplava, sim o econômico, como voltar a produção para o mercado interno em aproveitamento dos recursos e potencialidades nacionais, concomitantemente com melhor distribuição de renda para permitir acesso da maioria da população aos bens e serviços produzidos. Mas, não só, aspectos não-econômicos deveriam estar presentes nessa proposição. Para tanto, realçava que o indivíduo deveria ser valorizado, para que através de sua capacidade e criatividade pudesse ter atuação transformadora em sua realidade. Tais proposições deveriam se sustentar em uma estratégia de desenvolvimento voltada em reduzir da heterogeneidade econômica e permitir melhores condições sociais. Para tanto, requeria o 
exercício do Estado no papel de grande protagonista, elaborando planejamento adequado e utilizando corretamente seus instrumentos de política, na reconstrução econômica e social do país (FURTADO, 1994).

\section{PERSPECTIVA NEO-ESTRUTURALISTA DE DESENVOLVIMENTO EM FERNANDO FAJNZYLBER: PONTOS SELECIONADOS}

Uma das preocupações centrais de Fajnzylber refere-se ao processo de transnacionalização e seus efeitos sobre a dinâmica industrial das economias latinoamericanas. A expansão internacional das empresas era considerada parte do desenvolvimento capitalista mundial e vista como sujeito ativo do desenvolvimento, dado o papel dinâmico que exerciam em seus países de origem em termos de produção, investimento e pesquisa e desenvolvimento (Fajnzylber, 1976). Por consequência, esperava-se que as empresas multinacionais viessem, ao adentrarem a América Latina, impor novo estilo de desenvolvimento. Havia expectativa positiva que viessem exercer o poder de irradiação produtiva, tecnológica e exportadora, bem como provocassem mudanças na estrutura social, através da geração de emprego e renda correspondentes.

Para os países latino-americanos, a vinda do investimento direto externo era reconhecidamente uma forma de suprir a escassez de recursos financeiros para impulsionar o desenvolvimento produtivo, amenizar o estrangulamento externo no balanço de pagamento e reduzir problemas decorrentes a desvantagens tecnológicas. Neste curso, os Estados Nacionais se empenharam em criar condições de atração, através da promoção de condições infraestruturais - energia, transporte e comunicação - sistemas de incentivos fiscais e financeiros, regime cambial favorável, proteção de mercado, facilidade de remessa de lucros, entre outros benefícios (FAJNZYLBER, 1976).

Contudo, os estudos realizados sobre o sistema de industrial do Brasil e do México, tanto na perspectiva do funcionamento interno como de sua estreita vinculação com o processo de internacionalização, mostraram os limites das expectativas geradas pela importância das multinacionais no processo de desenvolvimento periférico. Fajnzylber constatou que o estilo de desenvolvimento, com forte presença dessas empresas, foi marcado pela implementação de um padrão de produção à semelhança dos países centrais; constituição de mercado consumidor para classes médias e altas; destino das atividades econômicas, em grande monta, para o mercado interno; adoção de tecnologia 
em processo de esgotamento e uso difundido; despreocupação com a área de pesquisa e desenvolvimento; baixa articulação com empresas nacionais; forte concentração em setores econômicos dinâmicos; e, influenciadoras nas decisões políticas dos Estados Nacionais (FAJNZYLBER, 1979).

No âmago do processo de desenvolvimento latino-americano, Fajnzylber posicionava criticamente ao protecionismo de mercado concedido às empresas multinacionais, e por extensão, às empresas nacionais pelos Estados Nacionais. $O$ protecionismo, gerador de reserva de mercado, era alto, genérico, não seletivo, sem propósito definido e sem prazo para terminar. Em sua opinião, o Estado demonstrava a atitude passiva, em atender interesses privados em detrimento do interesse da Nação. Nessa demonstração, mostrava-se frágil e contribuía para a deformação do padrão de industrialização latino-americano, pouco exposto à concorrência externa e fomentador da concentração empresarial. Além disso, a decisão estatal em favor do sistema de proteção não promovia as aprendizagens produtiva e tecnológica, que favorecessem a indústria nacional, bem como não orientava a formação de uma estrutura produtiva que aproveitasse as potencialidades humanas e recursos naturais, em benefício da maioria da sociedade (FAJNZYLBER, 1979).

Nesse curso, as empresas multinacionais não desencadearam processo de destruição criadora, como proposto por Schumpeter (1982). A expressão: “(...) la fase creadora de estas atividades no se realizam localmente" (Fajnzylber; Tarragó, 1976, p. 644, apud Paiva, 2006, p. 68), sinalizava o descompromisso dessas empresas em promover mudanças técnicas impulsionadoras do desenvolvimento. Por outro lado, trouxeram para os países hospedeiros, tecnologias já em uso, nem sempre atualizadas. Em linha, afirmou: “(...) tanto os produtos fabricados como os equipamentos e processos de produção utilizados na América Latina não pertencem, em geral, a geração tecnológica mais recente" (FAJNZYLBER, 1979, p. 188). Apontou: “(...) la tecnologia desplezada hacia las filiais de los países subdesarrollados es la que, de acuerdo a la teoria del ciclo de produto corresponde, a la fase de produtos de origem estandardizados, es decir, a la fase final de ciclo iniciado com la innovación em el país de origen alguns años atrás" (PAIVA, 2006, p, 95, FAJNZYLBER; TARRAGÓ, 1976, p. 100).

As empresas multinacionais encontraram terreno fértil para expansão nos segmentos econômicos inexistentes, como de bens de capital e bens de consumo duráveis, e, em setores já estabelecidos, como de bens de consumo final. Para Fajnzylber (1976), a presença significativa de empresas forânea influenciava e direcionava a expansão industrial 
dos países latino-americanos. Com isso, as empresas nacionais foram deslocadas para a posição inferior na matriz industrial frente o peso das empresas forâneas. Assim, observou “(...) provoca um desplazamento de poder desde agentes económicos nacionales hacia agentes económicos, cuya propriedade y direcion está em el exterior (...)" (Fajnzylber; Tarragó, 1976, p. 647, apud Paiva, 2006, p, 97,). Enquanto, nos países de origem das empresas transnacionais, políticas industriais ativas garantiram poder de concorrência às empresas domésticas e foram estabelecidos regramentos disciplinadores das atividades exercidas por multinacionais, no terreno doméstico.

Fanjzylber entendia que além da dimensão econômica, o processo de transnacionalização das economias latino-americanas continha dimensão política. As empresas multinacionais produziam efeitos político norteando o estilo de desenvolvimento, tornando as economias refém de seus objetivos. Com presença em setores considerados dinâmicos da estrutura industrial, as empresas forâneas passaram a requerer cada vez mais investimentos públicos em sua promoção. Assim os investimentos públicos passaram a ser definidos pela dinâmica dos investimentos privados forâneos, impondo assim estilo de desenvolvimento seletivo (FAJNZYLBER, 1976).

Além disso, os interesses dos consumidores, os fornecedores e credores domésticos entrelaçaram com os interesses das empresas multinacionais, dada a internacionalização do sistema produtivo e do mercado consumidor doméstico. O posicionamento de Fajnzylber encontrava-se em linha com os escritos de Cardoso e Faletto (1979), que demonstraram, no campo da sociologia, o entrelaçamento dos interesses políticos das classes dominantes interna e externa, em prejuízo da construção de uma industrialização de interesse nacional, que pautasse pelo desejo de construir o desenvolvimento econômico de forma autônoma.

Para enfrentar os vínculos de interesse da burguesia nacional com o capital internacional que limitavam o desenvolvimento autônomo, Fajnzylber pregava a necessidade de o Estado controlar a atuação das empresas multinacionais. Tinha clara a visão de que tais empresas aproveitaram das condições propiciadas e não geraram condições de promoção do desenvolvimento econômico sustentável na região (FAJNZYLBER, 2006b). Paiva (2006, p. 110) sintetiza as condições encontradas pelas multinacionais que reforçavam a postura de serem menos eficientes, do que nos países de origem: "A ausência de políticas destinadas a orientar a atuação da ETs na América Latina, a ineficiência das barreiras à entrada, os níveis elevados de proteção, a inexistência de concorrência interna, a competição via diferenciação de produtos e a possibilidade das ETs adquirem tecnologia transferida da matriz". 
Fajnzylber direcionou seus estudos para compreender o processo de industrialização dos países avançados e dos novos países asiáticos, no propósito de propor condições que superasse o comportamento passivo e imitativo, que caracterizou a industrialização latino-americana. Os estudos sobre políticas desenvolvimentistas empreendidas pelos Estados Unidos, Alemanha, Japão e Coreia do Sul deram condições de propor elementos para construção de desenvolvimento industrial autônomo e dinâmico. Nesses, observou que os tais países desenvolveram ações - orientação, recursos e pesquisas - voltadas em superar a elevação de custos produtivos - mão de obra e insumos -, bem como aproveitaram as oportunidades tecnológicas abertas por insumo essencial petróleo e subprodutos - e desenvolveram, prioritariamente, as indústrias de bens de capital e química, consideradas portadoras do progresso técnico, pelos efeitos irradiadores gerados para a estrutura industrial (FAJNZYLBER, 1983; SILVA, 2014.).

Nos estudos sobre padrão de industrialização diferenciado, Fajnzylber compreendeu que cada país desenvolvera estratégias próprias e modelo de desenvolvimento distintos, dada as diferentes condições históricas, econômicas, políticas e sociais. Observou em alguns países, sobretudo nos asiáticos, a coexistência de planejamento e mercado, sendo o planejamento construído a partir dos objetivos de médio e longo prazos, segundo os interesses da sociedade. Nesse contexto, reconheceu o papel importante do Estado orientando investimentos, selecionando setores prioritários, criando ambiente institucional e macroeconômico favorável e investindo em educação, saúde e infraestrutura (FAJNZYLBER, 1983).

Destarte, constatou, ainda, a construção de alianças sociais, formada por várias categorias de atores - trabalhadores, empresários, agricultores, técnicos, cientistas, funcionários públicos, associações de classes, etc. - que sustentaram, politicamente, o padrão de industrialização construído. Acrescentou, ainda, que nesses países existiam um núcleo empresarial nacional com vocação industrializadora; setor financeiro subordinado aos objetivos estratégicos da industrialização; e, em dimensão menor, empresas multinacionais subordinadas aos objetivos estratégicos definidos internamente (FAJNZYLBER, 1983; SUZIGAN; PAIVA, 2004).

Para Fajnzylber, a industrialização na América Latina mostrou-se trunca e distorcida. Demonstrou que a estrutura produtiva era atrasada e demonstrava várias incapacidades: de atender as carências sociais, de desenvolver padrão compatível com as potencialidades internas e de construir matriz industrial e produtiva articulada setorialmente. Contribuíam, para tanto, empresariado sem inclinação inovadora schumpeteriana e incapaz de articular 
uma estratégia nacional de desenvolvimento; política governamental favorecendo a ineficiência pela prática de protecionismo frívolo; falta de legislação adequada para orientar a atuação das empresas estrangeira; ausência de uma política de aprendizagem industrial; pouco desenvolvimento da indústria de bens de capital; baixa interação da agricultura com setores industriais; e, ausência de um núcleo endógeno de desenvolvimento tecnológico (FAJNZYLBER, 1983).

Este último fator, ausência de um núcleo endógeno de desenvolvimento tecnológico, constitui um fator explicativo maior pela disfuncionalidade da estrutura industrial construída na América Latina. As economias regionais mostravam-se incapaz de "abrir a caixa preta" do progresso técnico", não se aproveitando o valor intelectual dos recursos humanos e naturais para promoção do desenvolvimento. Os segmentos detentores do progresso técnico internos eram precários, com isso tornava-se incapaz de adequar um padrão produtivo que atendesse as necessidades e a riqueza dos países. Afirmou, Fajnzylber (1983, p. 301), que sem esse núcleo irradiador do progresso técnico, se perdia a oportunidade de "avanzar em el aprovechamiento de las potencialidades em el ámbito de recursos naturales o mano de obra y para adecuar el patrón de consumo cósmico a las especificidades de la condiciones locales".

Nesse quadro, a indústria de bens de capital teria papel central no cumprimento de funções ditadas pelo núcleo de desenvolvimento endógeno da dinamização tecnológica. A partir dessa indústria, seriam provocados efeitos positivos à montante e à jusante na estrutura industrial, pois máquinas e equipamentos fabricados por esse segmento impactariam diversos outros segmentos econômicos. No quadro existente, os bens de capital vinham dos países desenvolvidos e os fabricados internamente eram de baixa complexidade tecnológica. Além disso, afirmava que nos países latino-americanos existiam tarifas favoráveis às importações de máquinas e equipamentos, bem como financiamento externo atrativo para aquisição fabricadas no exterior, desencorajando, assim, a produção de bens de capital local.

O núcleo endógeno de dinamização tecnológica, segundo Paiva (2006, p. 195) levaria a "criação e a articulação de uma matriz industrial e produtiva capaz de gerar o progresso técnico, tanto através da adaptação do acervo tecnológico adquirido internacionalmente, como pela via do desenvolvimento interno de inovação. Com base nesse núcleo, a geração, adaptação e incorporação do progresso técnico elevam a produtividade e aumentam a competitividade nos mercados internacionais". Esse núcleo permitiria, além de inserção ativa nos processos produtivos domésticos, acompanhar o que 
estava sendo gestado de novo no padrão tecnológico mundial. Estaria, com tal constituição criando condições de desenvolvimento de uma competitividade sistêmica autêntica e dinâmica, fundada no desenvolvimento inovativo e não em uma competitividade espúria e estática, construída a partir de baixos salários, câmbio favorável, subsídios e incentivos fiscais (SUZIGAN; PAIVA 2004).

O núcleo endógeno de dinamização tecnológica para Fajnzylber, deveria estar articulado com a estrutura produtiva, assegurando diversos processos: assimilação, aprendizagem, adaptação e inovação. Nessa perspectiva, estavam sendo dadas as condições para que através da criatividade possibilitasse o surgimento de novos produtos, novos processos e novas organizações. A materialidade dessa estratégia, dependia de arranjos que resultassem em: mudanças institucionais - leis, regras, incentivos, penalizações -; modificação no padrão de investimento; constituição de sistema de financiamento; ampliação das bases de sustentação - empresários e trabalhadores; e, atuação do Estado na eleição de setores prioritárias, na criação de ambiente macroeconômico estável e em investimentos sociais - educação e saúde -, infraestruturais - energia, transporte e comunicação - e tecnológicos - pesquisa e desenvolvimento (PAIVA, 2006; SUZIGAN; PAIVA, 2004; IPIRANGA; BITTENCOURT, 2018). Considerando as características desse arranjo, Fajnzylber, sem dúvida, foi um dos primeiros na América Latina a desenvolver a ideia de sistema de inovação, como condição para o desenvolvimento tecnológico.

Nesse sentido, sustentado por um conjunto de esforços coordenados de caráter sistêmicos, estariam sendo dadas as condições de reestruturar o aparato produtivo através da constituição de um núcleo endógeno de dinamização tecnológica, que se articularia com setores de maior conteúdo tecnológico na promoção do crescimento econômico. Sob nova orientação estratégica, a transformação produtiva resultaria em crescimento econômico com equidade social. (FAJNZYLBER, 2006a). Na leitura de Fajnzylber, países de industrialização tardia, (Coreia do Sul, p.ex.), atingiram os dois objetivos de forma simultânea. Enquanto, países da América Latina, (Brasil, p. ex.) alcançaram crescimento sem distribuição de renda, por consequência, excluindo parte da sociedade de acesso aos frutos desse crescimento. Situação essa, denominada de síndrome do "casillero vacio", a partir de estudo sobre o desenvolvimento de países da região que tiveram bastante dinamismo e pouca articulação social (FAJNZYLBER, 1990).

Para Fajnzylber, não era contraditório e sim virtuosa a relação entre crescimento econômico e equidade social. Para tanto, investimentos produtivos impulsionariam o 
crescimento econômico, geradores de produtos e serviços competitivos. Em paralelo, estabeleceria padrão de consumo austero, gerador de poupança financiadora de investimentos. Bem como, se adotariam ações que favorecessem a distribuição de renda, que permitisse o acesso da população a saúde, educação, capacitação, previdência social e habitação. A declaração referenda: “(...) el crescimento apoyaria a la equidade y la equidade apoyaria al crescimento em la medida em que coexistisen um sistema industrial competitivo y um patrón de consumo y de inversion más austeros e productivos" (FAJNZYLBER, 1990, p. 67).

Tal construção não seria criada através das forças de mercado, mas por ação dirigida pelo Estado. Em correspondência, afirmou “(...) la acción del Estado debe estar encaminhada a crear las condiciones que permitan la concertación estratégica entre los agentes públicos y privados para inducir um processo de transformación productiva que genere estructuras internacionalmente competitivas y socialmente equitativas (FAJNZYLBER; SCHEJTMAN, 1995, p. 191). Para tanto, o Estado deveria estabelecer objetivos de médio e longo prazos a partir dos interesses da sociedade. Nesse contexto, se definiriam orientações fundamentais com relação aos programas de investimento nos setores estratégicos, estabelecendo instrumentos e critérios apropriados para adequar o planejamento estatal com as condições do mercado. Deveria, também, o Estado manter um ambiente macroeconômico estável e estabelecer seleção de programas de educação, saúde, transporte, energia, pesquisa e desenvolvimento (PAIVA, 2006).

\section{PONTOS CONVERGENTES DAS CONCEPÇÕES ANALÍTICAS DE FURTADO E FAJNZYLBER}

Do exposto na seção 2 para o estruturalismo de Celso Furtado e na seção 3 para o neoestruturalismo de Fernando Fajnzylber, verifica-se a existência de diversos pontos convergentes relacionados com as concepções analíticas e preocupações desenvolvimentistas na América Latina. São destacadas convergência nos temas sobre importância do desenvolvimento do progresso técnico para domínio tecnológico e produtivo; posicionamento crítico em relação ao desempenho do capital estrangeiro nas economias periféricas; avaliação de experiências de desenvolvimento de países que superaram a dependência; relevância do papel do Estado na criação de condições de 
desenvolvimentista; e construção de projeto nacional de desenvolvimento que leve em pauta não só a dimensão econômica, mas a dimensão social.

O primeiro ponto de convergência a ser ressaltado é o papel central dado para as inovações tecnológicas no processo de desenvolvimento econômico em ambas as abordagens teórico-analíticas. Tanto em Furtado quanto em Fajnzylber, as inovações tecnológicas essenciais ao desenvolvimento do capitalismo industrial. Segundo Furtado, o padrão de progresso técnico adotado na periferia, entretanto, sob comando de grandes empresas multinacionais monopolistas detentoras de tecnologia vinda do exterior, era fator estranho para a promoção do desenvolvimento, pois não envolvia expansão da massa salarial e elevação do padrão de vida da população como ocorria nas economias desenvolvidas. A simples transferência de capital e técnicas do centro para a periferia, como o Brasil, não era capaz de criar uma indústria nacional autônoma.

Neste mesmo sentido, Fajnzylber destacou a ausência de um núcleo endógeno de desenvolvimento tecnológico na periferia, isto é, ausência de segmentos nacionais detentores do progresso técnico, como fator explicativo da inadequação da estrutura industrial construída países latino-americanos em atender as necessidades e riquezas desses países. A construção deste núcleo permitiria a indústria nacional acompanhar o estado atual e o que estava sendo gestado de novo no padrão tecnológico mundial, criando, assim, condições de desenvolvimento de uma competitividade autêntica e dinâmica, baseada no desenvolvimento inovativo e tecnológico.

Esse referendo possibilita chamar atenção para o segundo ponto de convergência, de importância essencial em ambos os autores em relação a percepção do comportamento adverso das empresas de capital estrangeiro para o desenvolvimento econômico dos países da América Latina. Em ambas perspectivas se entende que o capital estrangeiro tem amplo domínio de diversos setores da indústria nos países periféricos, sobretudo nos considerados dinâmicos - bens de capital e bens de consumo duráveis, ao passo que o capital nacional era visto como débil e incapaz de ter participação ativa na estrutura produtiva doméstica. O empresariado nacional apresentava características que justificava tal postura: incapacidade de comando, falta de mentalidade empreendedora, busca pelo lucro fácil, caminho fácil pela imitação e permanente estado de desânimo em Furtado; e, precariedade da vocação industrial e sem inclinação schumpeteriana em Fajnzylber.

Para Furtado, esse domínio do capital multinacional colocava os interesses econômicos estrangeiros em posição superior ao interesse nacional dos países periféricos. Tais interesses estrangeiros, conflitantes com os nacionais, debilitavam o processo de 
desenvolvimento econômico, nos níveis micro - subordinando e desarticulando as decisões das empresas nacionais - e macroeconômicos - impactando os preços básicos da economia nacional. Assim, ainda que a industrialização fosse central para o processo de desenvolvimento na visão furtadiana, ela não era suficiente, dado que esta industrialização na periferia estaria submetida ao domínio do capital estrangeiro, que dominava a tecnologia em vigor e não trazia efeitos sociais abrangentes. Nesse curso imperava a dependência cultural, visto que os padrões de consumo dos países centrais eram replicados na periferia, modernizando hábitos de consumo de acordo com a sua evolução cultural, entretanto, limitados à apenas uma pequena parcela da população.

De maneira similar, Fajnzylber entendia que o capital estrangeiro desempenha papel limitado no plano de desenvolvimento na periferia, frustrando as expectativas positivas em termos de geração de renda e emprego. Esse papel limitado podia ser visto em diversos âmbitos da atuação das empresas de capital estrangeiro, porém era mais saliente no âmbito tecnológico. O estilo de desenvolvimento com forte participação das empresas estrangeiras foi marcado, dentre outras coisas, pela adoção de tecnologias de uso difundido e em processo de esgotamento do seu potencial dinâmico, e pela despreocupação com a área de pesquisa e desenvolvimento (P\&D). Para Fajnzylber as empresas multinacionais não realizavam, localmente, os processos de destruição criadora impulsionadora do desenvolvimento. Através da sua influência política junto aos Estados Nacionais, as empresas multinacionais norteavam o estilo de desenvolvimento e tornavam as economias periféricas reféns de seus objetivos.

Em terceiro, tanto Furtado quanto Fajnzylber lançaram mão de estudos de caso relacionados com as experiências de desenvolvimento de diversos países, em especial os países do Leste Asiático. Tais estudos tinham uma função importante, obter conhecimento como esses países conseguiram impor estilo de desenvolvimento mais autônomo e menos dependente. Furtado, estudando os casos da Rússia, China, Japão, Coréia do Sul e Taiwan, demonstrou como foi possível a recuperação da soberania nacional, através de projetos de desenvolvimento com foco em transformações econômicas e sociais, e a interrupção da transmissão do centro para a periferia de valores culturais que realimentavam as condições de subdesenvolvimento e dependência externa. Fator central para essa superação foi a promoção da criatividade humana interna, através de novas ideias, novos esforços e novos propósitos orientados a buscar soluções para os problemas estruturais e superar o atraso econômico e social dos países. 
Fajnzylber, por sua parte, estudou os mecanismos, políticas e resultados alcançados pelos Estados Unidos, Alemanha, Japão e Coréia do Sul, e identificou esforços direcionados ao desenvolvimento industrial autônomo e dinâmico, em detrimento do comportamento passivo e imitativo que caracterizava a industrialização latino-americana. Em seus estudos, observou que cada país desenvolveu suas próprias estratégias e modelos de desenvolvimento distintos, de acordo com as suas diferentes condições históricas, econômicas, políticas e sociais, com vistas aos interesses da sociedade. Neste sentido, tanto Furtado quanto Fajnzylber destacaram a importância da criação de estratégias de desenvolvimento autênticas.

Outra convergência, a quarta, refere-se ao papel do Estado para a superação dos problemas que se colocam à frente do desenvolvimento econômico dos países da América Latina. Para Furtado tratava-se ator fundamental na promoção do desenvolvimento econômico, dada as carências estruturais existentes, desempenhando papéis de produtor, interventor, controlador, planejador, financiador e gestor. Para tanto, deveria recuperar a posição de centro básico de decisão, sob influência do capital estrangeiro e de parte do capital nacional associado. Enfatizou que o Estado deveria ter controle sobre as multinacionais, via apropriação de parte dos lucros; subordinação às diretrizes de política econômica, atendimento de objetivos sociais e interesses nacionais; e, priorizar o mercado interno e a criação de empregos. E, ressaltou o papel do Estado no fomento da criatividade através da atuação ativa na coordenação, promoção e seleção de investimentos públicos e privados, na formação de recursos humanos, no fomento à $P \& D$, etc.

Para Fajnzylber sinalizava que o Estado, através do uso da política, deveria ter controle sobre a atuação das empresas de capital estrangeiro, posto que tais empresas não desempenhavam papel ativo para o desenvolvimento econômico da região. A ausência dessas políticas voltadas ao interesse nacional contribuiu para que as empresas multinacionais desenvolvessem filiais menos eficientes do que as das matrizes em seus países de origem. Beneficiavam do protecionismo frívolo de mercado, regime fiscal financeiro barateador de investimento e descompromisso com transferência tecnológica via mecanismos de aprendizado, entre outros aspectos. Para tanto, o Estado deveria ser reestruturado com novas funções na orientação dos investimentos, na seleção de setores estratégicos, na criação de ambientes institucional e macroeconômico favoráveis e no investimento em áreas como educação, saúde e infraestrutura. Deveria exercer papel importante na construção da competitividade sistêmica, para que os países latinoamericanos tivessem inserção ativa na economia internacional. 
E, por fim, como quinta convergência, a preocupação de ambos na construção de um projeto de desenvolvimento, que possibilitasse transformações econômicas levando em conta a dimensão social. Furtado defendia o domínio do progresso técnico como instrumento para a periferia superar a dependência tecnológica que estava submetida. Mas, possuir condições domésticas para tal intento por si só, não levaria à superação do quadro existente. Conquistas nos campos macro e microeconômicas teriam sentido, se incorporasse um projeto social subjacente. Para tanto, novo estilo de desenvolvimento deveria ser construído, a partir de um Projeto de Nação. Esse, deveria ter propósito de superar o paradigma tecno-produtivo-distributivo anterior e expressar criatividade no desenvolvimento de condições materiais (econômicas) e não materiais (humanas) para transformar a realidade socioeconômica existente.

Fajnzylber pregava novo estilo de desenvolvimento para a América Latina, que pautasse pela transformação produtiva em que crescimento econômico e equidade social ocorressem conjuntamente. $\mathrm{O}$ crescimento do produto alcançado através de investimento e de emprego deveria ocorrer acompanhado de objetivos sociais. Tal intento não seria realizado simplesmente pelas forças de mercado, mas pela atuação ativa do Estado através de planejamento de médio e longo prazo. Essa ação seria em harmonia e em articulação com as condições de mercado. O planejamento estatal deveria definir setores prioritários estratégico impulsionadores do desenvolvimento. Estabelecer políticas e instrumentos que impulsionassem os investimentos produtivos e melhorassem a distribuição de renda e programas nas áreas da educação, saúde, habitação, saneamento e outras. Com isso, se estaria criando condições para o estabelecimento de uma sociedade mais socialmente equânime, dado o quadro latino-americano ser de tratamento não isonômico e imparcialidade aos diferentes atores no atendimento das necessidades sociais.

E, em complemento, sintetizam-se, no Quadro 1, pontos convergentes selecionados do tratamento analítico sobre desenvolvimento econômico apresentados por Furtado e Fajnzylber. 
Quadro 1 - Destaque de pontos de convergência selecionados na visão desenvolvimentista de Furtado e Fajnzylber.

\begin{tabular}{|c|c|c|}
\hline $\begin{array}{l}\text { Pontos de } \\
\text { convergência }\end{array}$ & Furtado & Fajnzylber \\
\hline Progresso Técnico & $\begin{array}{l}\text { Centralidade do progresso técnico no } \\
\text { processo de desenvolvimento. Padrão } \\
\text { de progresso técnico adotado na } \\
\text { periferia, sob comando de } \\
\text { multinacionais detentoras de } \\
\text { tecnologia, era fator estranho para a } \\
\text { promoção do desenvolvimento. }\end{array}$ & $\begin{array}{l}\text { Ênfase ao progresso técnico como } \\
\text { impulsionador do processo de } \\
\text { desenvolvimento. Defesa da criação } \\
\text { de núcleo endógeno de } \\
\text { desenvolvimento tecnológico na } \\
\text { periferia para potencializar as } \\
\text { condições de desenvolvimento. }\end{array}$ \\
\hline Capital Estrangeiro & $\begin{array}{l}\text { Domínio do capital estrangeiro em } \\
\text { diversos setores da indústria nos } \\
\text { países periféricos. Impõe padrão de } \\
\text { produção e consumo dos países } \\
\text { centrais. Coloca os interesses } \\
\text { estrangeiros sobre os interesses } \\
\text { nacionais e debilita o processo de } \\
\text { desenvolvimento. }\end{array}$ & $\begin{array}{l}\text { Domínio do capital estrangeiro em } \\
\text { setores dinâmicos da indústria nos } \\
\text { países periféricos. Uso de tecnologia } \\
\text { difundida. Empresas forâneas não } \\
\text { desempenham localmente os } \\
\text { processos de destruição criadora } \\
\text { que impulsiona o desenvolvimento. }\end{array}$ \\
\hline $\begin{array}{l}\text { Desenvolvimento } \\
\text { Econômico } \\
\text { Comparado }\end{array}$ & $\begin{array}{l}\text { Estudo dos casos da Rússia, China, } \\
\text { Japão, Coréia do Sul e Taiwan para } \\
\text { compreender processos de } \\
\text { superação do atraso. Cada país } \\
\text { estabeleceu estratégias em defesa da } \\
\text { soberania nacional. Destaque para a } \\
\text { criatividade - novas ideias, novos } \\
\text { esforços e novos propósitos - como } \\
\text { fator central para a superação do } \\
\text { subdesenvolvimento. }\end{array}$ & $\begin{array}{l}\text { Estudo dos casos dos Estados } \\
\text { Unidos, Alemanha, Japão e Coréia } \\
\text { do Sul para verificar fontes } \\
\text { promotoras do desenvolvimento. } \\
\text { Cada país desenvolveu suas } \\
\text { próprias estratégias e modelos de } \\
\text { desenvolvimento, de acordo com as } \\
\text { suas diferentes condições históricas, } \\
\text { econômicas, políticas e sociais. }\end{array}$ \\
\hline Papel do Estado & $\begin{array}{l}\text { Estado assumindo papel relevante na } \\
\text { superação do subdesenvolvimento. } \\
\text { Funções a desempenhar: produtor, } \\
\text { regulador e interventor. Em destaque } \\
\text { controlar as multinacionais, } \\
\text { subordinando essas empresas às } \\
\text { diretrizes de política econômica e aos } \\
\text { interesses nacionais. Fomentar a } \\
\text { criatividade, impulsionar o progresso } \\
\text { técnico e dar atenção à dimensão } \\
\text { social }\end{array}$ & $\begin{array}{l}\text { Importância do Estado em criar } \\
\text { condições para o desenvolvimento. } \\
\text { Para tanto, deve ser reestruturado } \\
\text { com funções de controlar atuação } \\
\text { das multinacionais, orientar } \\
\text { investimentos, selecionar setores } \\
\text { estratégicos, promover mudanças } \\
\text { institucionais, criar ambiente } \\
\text { macroeconômico e condições } \\
\text { sociais favoráveis. }\end{array}$ \\
\hline $\begin{array}{l}\text { Projeto Nacional de } \\
\text { Desenvolvimento }\end{array}$ & $\begin{array}{l}\text { Projeto desenvolvimento com } \\
\text { rompimento do paradigma produtivo- } \\
\text { distributivo anterior. Aproveitamento } \\
\text { dos recursos e potencialidade } \\
\text { nacional. Ênfase aos aspectos } \\
\text { materiais (econômicos) e não } \\
\text { materiais (indivíduo). Programação } \\
\text { para reduzir a heterogeneidade } \\
\text { estrutural econômica com projeto } \\
\text { social subjacente. }\end{array}$ & $\begin{array}{l}\text { Planejamento de médio e longo } \\
\text { prazos, com prioridades de } \\
\text { investimento em setores } \\
\text { estratégicos, criação de núcleo } \\
\text { endógeno de desenvolvimento } \\
\text { tecnológico, ênfase na distribuição } \\
\text { de renda e em programas sociais } \\
\text { (educação, saúde, habitação). } \\
\text { Planejar a transformação produtiva } \\
\text { com equidade social. }\end{array}$ \\
\hline
\end{tabular}

Fonte: Elaborado pelos autores. 


\section{CONCLUSÕES}

O presente trabalho apresentou preocupações com o desenvolvimento de Furtado e de Fajnzylber, em que ambos acreditavam na mudança estrutural como meio de alcançar maior competitividade no sistema produtivo e promover equidade social aos países latinoamericanos. As mudanças estruturais que acompanham o processo de industrialização associado a inovações tecnológicas promoveriam o aumento da produtividade do trabalho, a integração do mercado nacional, estimulando o aumento do emprego, a renda global e o bem estar social da população. Contudo, no curso do desenvolvimento, os anos foram mostrando a manutenção da heterogeneidade econômica e a permanência da exclusão social de grande parte da população dos bens e serviços produzidos. Razão dos esforços analíticos empreendidos, voltados em compreender tais processos e propor alteração no estilo de desenvolvimento empreendido.

Furtado chegou à conclusão que a industrialização por si só não levaria ao desenvolvimento dos países periféricos, que apresentam processos históricos, econômicos e sociais distintos das trajetórias dos países centrais. Subdesenvolvimento muito mais que a falta de capital, era produto das relações do sistema econômico mundial, que apresenta capacidades assimétricas de introduzir e de difundir o progresso técnico. Construiu-se um padrão de desenvolvimento associado com a internacionalização da economia, segundo padrões de produção e de consumo dos países centrais. Com isso, instaurou-se no Brasil uma situação de dependência tecnológica e cultural ao capital externo. Para tanto, o capital estrangeiro deveria ser supervisionado e orientado pelo Estado, com o intuito de que a nova tecnologia/conhecimento modernizasse a estrutura produtiva e internalizasse o processo de produção da riqueza nacional.

Ressaltou que o progresso técnico adotado nas economias de periferia não foi desencadeador do desenvolvimento, como é nas economias desenvolvidas. Trouxe, como resultado, benefícios para grupos sociais de elevada renda e integrados nos segmentos produtivos de bens de capital e de consumo duráveis e não conseguiu elevar o padrão de vida da população. Por sua vez, estudos sobre novos países industrializados - Coreia do Sul e Taiwan - que superaram o subdesenvolvimento com uma atuação do Estado em políticas de investimentos seletivos, formação de recursos humanos, fomento a P\&D e inovações tecnológicas, acendeu uma nova esperança. Esse caminho seria possível se adotasse estratégia soberana e audaciosa para superar a dependência externa. Transpor 
a barreira da dependência tecnológica e dos conhecimentos para a geração e difusão do progresso técnico seria determinante. O caminho seria através de um projeto nacional, em que a dimensão social necessariamente deveria ser incorporada à econômica.

Por sua vez, Fajnzylber, dedicou grande parte de seus estudos aos temas centrais do desenvolvimento, com a atenção voltada às empresas transnacionais e seus efeitos sobre a dinâmica industrial das economias latino-americanas. Reconheceu que a formação de uma base tecnológica e industrial era o caminho para alcançar um processo de desenvolvimento para a região. A vinda de investimento direto do exterior era reconhecida como uma forma de suprir a escassez de recursos financeiros, amenizar a balança de pagamento e reduzir as desvantagens tecnológicas dos países América Latina. Os Estados Nacionais possibilitaram infraestrutura, incentivos fiscais, proteção do mercado, remessa de lucros, entre outros benefícios. Entendia-se que seria o caminho para conciliar o crescimento econômico com padrões de equidade satisfatórios, e estaria rompendo com estrutura históricas concentradoras e excludentes.

Contudo, estudos realizados sobre as estruturas industriais do Brasil e do México, demonstraram que a industrialização destes países não fora capaz de sustentar um desenvolvimento tecnológico local e elevar a competitividade internacional. A liderança exercida pelas empresas transnacionais determinava o estilo de desenvolvimento exercida nos setores mais dinâmicos da economia através do domínio da tecnologia, de alta concentração da produção e de elevada capacidade financeira. Adotando tecnologias de uso difundido e voltadas para o mercado interno não geravam efeitos irradiadores para o desenvolvimento. Somam-se a esse quadro, outras características limitadoras, dentre as quais as características passiva, amorfa e imitativa do empresariado nacional e de um Estado beneficiador de condições para empresas forâneas, sem cobrança de contrapartidas, que viessem contribuir para o desenvolvimento autônomo dos países.

Fajnzylber procurou demonstrar que para a região se desenvolver era preciso reverter este quadro, a solução estaria pela abertura da caixa preta do progresso técnico. Contribuiu para tal defesa, os estudos sobre as experiências de desenvolvimento alcançada pelos países avançados e dos novos países industrializados asiáticos que elevaram a competitividade do setor industrial e voltaram-se ao comércio internacional a partir do desenvolvimento endógeno do progresso técnico. Logo, sugeriu que os países latinoamericanos a criação desse núcleo para superar o comportamento passivo e imitativo da industrialização e que satisfizesse as necessidades básicas da sociedade. Tal ação transformadora deveria ser acompanhada por medidas de promoção da equidade social, 
uma vez que não considerava antagônico o crescimento econômico e justiça social. Destarte, somente esse horizonte seria possível com atuação ativa do Estado, através de planejamento de médio e longo prazos e de criação de políticas e instrumentos adequados.

Nesses termos, existem pontos convergentes relacionados com as preocupações desenvolvimentistas de Furtado e de Fajnzylber. Ambos destacaram a importância do papel do Estado, no controle das multinacionais, na orientação dos investimentos e no fomento a criatividade. Para priorizar o interesse nacional e desempenhar localmente os processos de criação destruidora que impulsiona o desenvolvimento, atentaram para o controle do capital estrangeiro. As inovações tecnológicas e o progresso técnico para serem potencializados, defenderam a criação de estrutura endógena de desenvolvimento tecnológico para superação da dependência. Embasados em experiências de desenvolvimento de países, trouxeram modelo para a superação do subdesenvolvimento, atentando que se devem considerar as diferentes condições históricas, econômicas, políticas e sociais de cada país. Destarte, tais sinalizações somente seria possível a partir de planejamentos e projetos em que a dimensão econômica, ocorresse articulada com a dimensão social para que efetivamente viesse ocorrer o desenvolvimento econômico.

\section{REFERÊNCIAS}

ALMEIDA, J. E. Subdesenvolvimento e dependência: uma análise comparada de Celso Furtado e Fernando Henrique Cardoso. 205 fl. Tese (Doutorado em Economia), Programa de Pós-Graduação em Economia, Universidade Federal do Rio Grande do Sul, 2009.

CARDOSO, F. H. Empresariado industrial e desenvolvimento econômico no Brasil. São Paulo: Civilização Brasileira, 2ª . ed. 2000.

CARDOSO, F. H.; FALETTO, E. Dependência e desenvolvimento na América Latina: ensaio de interpretação sociológica. 5a . ed., Rio de Janeiro: Zahar, 1979.

FAJNZYLBER, F. Oligopólio, empresas transnacionales y estilos de desarollo. El Trimestre Económico, v. 43(3), n. 171, jul-set, 1976, p. 625-656.

FAJNZYLBER, F. A empresa internacional no processo de industrialização da América Latina. In: SERRA, J. (org.) América Latina: ensaios de interpretação econômica. Rio de Janeiro: Paz e Terra, 1979, p. 172-207.

FAJNZYLBER, F. Industrialización trunca de América Latina. Cidade do México. Nueva Imagem, 1983. 
FAJNZYLBER, F. Industrialización em América Latina: de ela cajá negra al casillero vacio. Santiago: Cuadernos de la CEPAL, 1990.

FAJNZYLBER, F. Progreso técnico y competitividade em América Latina. Industrialización y Desarollo Tecnológico, n. 12, abr, 1992, p. 27-42.

FAJNZYLBER, F.; SCHEJTMAN, A. Agricultura, indústria y transformación productiva. In: REYNA, J. L. América Latina a fine de siglo. Cidade do México: Fondo de Cultura Económica, 1995, 148-197.

FAJNZYLBER, F. Transformacion productiva con equidade. In: OLIVOS, M. T. (org.) Fernando Fajnzylber: uma visión renovadora del desarrollo em América Latina. Santiago: CEPAL, 2006a, p. 337-402.

FAJNZYLBER, F. Desarrollo productivo y empresas transnacionales em América Latina. In: OLIVOS, M. T. (org.) Fernando Fajnzylber: uma visión renovadora del desarrollo em América Latina. Santiago: CEPAL, 2006b, p. 105-142.

FAJNZYLBER, F; TARRAGÓ, T. Las empresas transnacionales: expansión a nível mundial y proyección em la indústria mexicana. Cidade do México: Fondo de Cultura Económica, 1976.

FURTADO, C. A economia brasileira: contribuição à análise do seu desenvolvimento. Rio de Janeiro: Ed. A Noite, 1954.

FURTADO, C. Subdesenvolvimento e subdesenvolvimento. Rio de Janeiro: Fundo de Cultura, 1961.

FURTADO, C. Dialética do desenvolvimento. Rio de Janeiro: Fundo de Cultura, 1964.

FURTADO, C. Subdesenvolvimento e estagnação na América Latina. Rio de Janeiro: Civilização Brasileira, 1966.

FURTADO, C. Um projeto para o Brasil. Rio de Janeiro: Editora Saga, 1968.

FURTADO, C. Formação econômica da América Latina. Rio de Janeiro: Lia Editora, 1970.

FURTADO, C. Análise do modelo brasileiro. Rio de Janeiro: Civilização Brasileira, 1972.

FURTADO, C. O mito do desenvolvimento econômico. Rio de Janeiro: Paz e Terra, 1974.

FURTADO, C. Criatividade e dependência na civilização industrial. Rio de Janeiro: Paz e Terra, 1978.

FURTADO, C. Teoria e política do desenvolvimento econômico. São Paulo: Abril Cultural, 1983a. 
FURTADO, C. El subdesarrollo latino-americano. Cidade do México: Fondo de Cultura Econômica, 1983b.

FURTADO, C. Brasil: a construção interrompida. Rio de Janeiro: Paz e Terra, 1992a.

FURTADO, C. O subdesenvolvimento revisitado. Economia e Sociedade, v. 1, n. 1, ago, 1992b, p. 5-19.

FURTADO, C. A superação do subdesenvolvimento. Economia e Sociedade, v. 3, n. 1, dez, 1994, p. $37-47$

FURTADO, C. Brasil: os caminhos da reconstrução. Revista Proposta, n. 82, p. 12- 18, set/nov, 1999a.

FURTADO, C. O longo amanhecer: reflexões sobre a formação do Brasil. $2^{\mathrm{a}}$. ed. Rio de Janeiro: Paz e Terra, 1999b.

FURTADO, C. Formação econômica do Brasil. 34a . ed. São Paulo: Companhia das Letras, 2007.

GUIMARÃES, V.; PEIXOTO, F.; CASIOLATO, J. E.; LASTRES, H. M. M. Convergências e complementariedades da corrente neo-schumpeteriana com o pensamentoe estruturalista de Celso Furtado. In: SABOIA, J.; CARVALHO, F. J. C. Celso Furtado e o século XXI. Barueri: Editora Manole, 2007, p. 205-238.

IPIRANGA, A.; BITTENCOURT, P. O caráter sistêmico do desenvolvimento tecnológico: uma aproximação entre a escola neoschumpeteriana e as visões de Fernando Fajnzylber. III Encontro Nacional de Economia Industrial e Inovação - ENEI. Uberlândia - MG, 18 a 20 de setembro, 2018.

LINS, L. C. O. Desenvolvimento social: o projeto de Celso Furtado para a nação brasileira. 149 fl. Dissertação (Mestrado em Economia) - Programa de Pós-Graduação em Economia - Universidade Federal de Santa Maria, 2013.

MELLO, J. M. C. O capitalismo tardio. São Paulo: Brasiliense, 1998.

PAIVA, S. C. Estratégias de política industrial e desenvolvimento econômico: ideias de Fernando Fanjzylber para a América Latina. 308 fl. Tese (Doutorado em Economia). Programa de Pós-Graduação em Economia Aplicada. Universidade Estadual de Campinas, 2006.

SCHUMPETER, J. A. Teoria do desenvolvimento econômico: uma investigação sobre lucros, capital, crédito, juro e ciclo econômico. São Paulo: Abril Cultural, 1982.

SILVA, R. L. M. A primazia de Fernando Fajnzylber na elucidação de aportes exógenos ao milagre sul-coreano. Cadernos do Desenvolvimento, Rio de Janeiro, v. 9, n. 15, jul-dez, 2014, p. 63-79.

SUZIGAN, W.; PAIVA, S. C. Competitividade sistêmica: a contribuição de Fernando Fajnzylber. História Econômica \& História de Empresas, v. 7, n. 2, 2004, 165-187. 
TAVARES, M. C. Da substituição de importações ao capitalismo financeiro: ensaios sobre economia brasileira. Rio de Janeiro: Zahar Editores, 1977.

TAVARES, M. C.; SERRA, J. Além da estagnação: uma discussão sobre o estilo de desenvolvimento recente no Brasil. In: BIELCHOWSKY, R. (org.) Cinquenta anos de pensamento na CEPAL. Rio de Janeiro: Record/CEPAL, 2000, p. 589-608.

TEIXEIRA, A. O movimento da industrialização nas economias capitalistas centrais no pós-guerra. $248 \mathrm{fl}$. Dissertação (Mestrado em Economia) - Programa de PósGraduação em Economia - Universidade Federal do Rio de Janeiro, 1983. 